\title{
PERCEPÇÃO MASCULINA SOBRE AS BARREIRAS DAS MULHERES EXECUTIVAS
}

\section{MALE PERCEPTION ON EXECUTIVE WOMEN BARRIERS}

\begin{abstract}
Andreia Cardoso
Formada em Administração de Empresas pela Universidade Anhembi Morumbi e com Pós-graduação em Gestão de Projetos pela Fundação Vanzolini - Escola Politécnica da USP. Atualmente cursando Mestrado em Administração de Empresas na Universidade Presbiteriana Mackenzie. Gerente de Controle Financeiro para America Latina da Ericsson Telecomunicações.

São Paulo, SP, Brasil

E-mail: andreia.cardoso@gmail.com
\end{abstract}

\section{Darcy Mitiko Mori Hanashiro}

Possui graduação em Economia pela Universidade de São Paulo, mestrado em Administração pela Universidade Federal do Rio Grande do Sul, doutorado em Administração pela Universidade de São Paulo e pós-doutorado na Alliant International University, Marshall Goldsmith Management School, San Diego, EUA. Professora Adjunta do Programa de Pós-Graduação em Administração de Empresas da Universidade Presbiteriana Mackenzie.

São Paulo, SP, Brasil

E-mail: darcyhanashiro@gmail.com

\section{RESUMO}

O ambiente de tecnologia é, hegemonicamente masculino e reflete a baixa proporção de mulheres nos cursos de graduação, nas áreas de Exatas e de Tecnologia. Diante desse cenário, é esperado que as mulheres encontrem mais barreiras para ascender em funções executivas nas áreas de tecnologia. Isso implica que os tomadores de decisão, no que concerne à carreira, supostamente, sejam homens. Assim, o objetivo deste estudo é identificar possíveis barreiras para a mulher atingir uma função executiva na área técnica, na perspectiva de homens executivos. Uma pesquisa qualitativa foi realizada, por meio de oito entrevistas semiestruturadas com homens executivos (diretores e gerentes) da área técnica de uma empresa multinacional de tecnologia. Os dados foram analisados mediante a técnica de categorização temática. Os resultados revelaram que, na percepção desses executivos, não existem barreiras significativas engendradas no ambiente organizacional, que dificultem ou impeçam as mulheres de ascender a posições executivas na área técnica. Todavia, eles apontaram barreiras advindas das próprias mulheres.

Palavras-chave: Mulheres Executivas. Carreira em Área de Tecnologia. Barreiras para Ascensão. Percepção Masculina. Estratégias para Ascensão.

\section{ABSTRACT}

The technology environment is hegemonically male and reflects the low proportion of women in undergraduate courses in the areas as Computer, Technology and Mathematical Sciences. In this scenario, it is expected that women find more barriers to ascend to executive positions. This means that the decision makers with regards to career are supposedly men. The objective of this study is to identify possible barriers faced by women to achieve executive positions in the technical area, from men executives perspective. A qualitative research was carried out through semi-structured interviews with eight male executives (managers and directors) from a technical area of a multinational technology company. The data were analyzed through thematic categorization technique. On the executive's perceptions, there are no significant barriers engendered in the organizational environment that could impede or prevent women from climbing up the ladder toward executive positions in the technical area. However, they pointed out barriers arising from women themselves.

Keywords: Executive Women. Technology Sector Career. Career Ascension Barriers. Male Perception. Ascension Strategies.

Data de aprovação: 23 de março de 2018.

Data de submissão: 16 de dezembro de 2016. 


\section{INTRODUÇÃO}

Os estudos sobre as barreiras profissionais enfrentadas pelas mulheres executivas abordam, predominantemente, a perspectiva das próprias mulheres, com respeito às atitudes preconceituosas, discriminação, percepção de serem consideradas com baixa capacidade de liderança, e o conflito entre trabalho e família. Um levantamento da literatura nacional e internacional, no período de 2001 a 2015, nas bases de dados Spell, Scielo, EBSCO, JSTOR e Proquest, utilizando as palavras male, man, men, gender, career, opinion, perception, woman, women, opinião, masculina, gênero, homens, carreira, e mulheres, não encontrou estudos, à luz da visão masculina, sobre as barreiras para a ascensão na carreira na área de tecnologia (Tecnologia da Informação e Comunicação) enfrentadas pelas mulheres. Este trabalho investiga esta lacuna na literatura, apresentando, portanto, o seguinte problema de pesquisa: Quais são as barreiras profissionais para as mulheres que atuam na área técnica de uma empresa de tecnologia, na perspectiva de homens executivos e tomadores de decisão?

O setor de tecnologia é considerando um ambiente dominado por homens, então pode-se supor que estes sejam maioria nos processos de tomada de decisão, inclusive nas deliberações sobre contratação e carreira de mulheres. Segundo os dados do Instituto Nacional de Estudos e Pesquisas Educacionais Anísio Teixeira (Inep), a quantidade de graduados nas áreas de Ciências Exatas, no Brasil, é muito inferior à quantidade de graduados nas áreas de Ciências Humanas. Um recorte por sexo mostra que o número de mulheres graduadas nas áreas de Ciências Exatas é ainda menor. Somente 13,7\% dos graduados no Brasil são das áreas de Ciências Exatas, sendo que apenas 31,1\% desses graduados são do sexo feminino. Assim, pode-se entender a razão pela qual a área de tecnologia é, tradicionalmente, masculina no Brasil. Diante desse cenário, o desafio para as mulheres que trabalham em empresas de tecnologia em ascender para cargos executivos parece ser ainda maior do que em outros setores.

Desta forma, o objetivo geral é identificar a existência de barreiras para a mulher atingir uma função executiva na área técnica, na perspectiva de executivos (diretores e gerentes) de uma empresa de tecnologia. Cabe salientar que as entrevistas foram realizadas por uma das autoras do artigo. Possíveis constrangimentos a este fato são comentados nas considerações finais.

Os resultados são relevantes para as organizações, pois podem contribuir para um entendimento mais crítico das práticas de diversidade e de inclusão de mulheres em posições estratégicas, em organizações de tecnologia.

Este artigo inicia com esta introdução, seguida por uma revisão da literatura. Na sequência é descrito o procedimento metodológico que orientou a pesquisa de campo. Em seguida, é apresentada a análise e discussão dos resultados. Na última parte do artigo articulam-se as considerações finais, as contribuições e limitações do estudo, além de uma agenda para futuras pesquisas. 


\section{FUNDAMENTAÇÃO TEÓRICA}

\section{Uma visão sobre o mercado de trabalho na área de tecnologia}

De acordo com os dados divulgados nos sites de algumas empresas de tecnologia (Figura 1), nota-se que o mercado mundial de trabalho nesta área é, predominantemente, ocupado por homens. Essas empresas possuem de $22 \%$ a $36 \%$ de mulheres no seu quadro de funcionários. Destacam-se a AT\&T e o Facebook, que figuram como os maiores empregadores de mulheres, com 36\% e 32\%, respectivamente. Contudo, especialmente em relação ao Facebook, a maioria dessas mulheres atua em áreas não técnicas (recursos humanos, marketing, etc.), e apenas $16 \%$ trabalham na área técnica.

A masculinização do mercado na área de tecnologia também se faz presente em países europeus. 0 relatório Woman active in the ICT sector, da Comissão Europeia (2013), revela que as mulheres representam $59 \%$ dos graduados em cursos superiores e 45,7\% do total de empregados na Europa. No entanto, elas constituem apenas 33\% dos graduados de Ciências Exatas e Tecnologia.

Essa condição espelha a proporção superior de egressos homens nas áreas de Engenharia, Produção, Construção, Ciências, Matemática e Computação, no Brasil, (Tabela 1), áreas que formam a base tradicional dos profissionais que atuam na área tecnológica das empresas. As mulheres, por seu turno, concentram-se nas áreas de conhecimento de Ciências Sociais e Ciências Sociais Aplicadas.

As mulheres representam $60,6 \%$ dos concluintes de graduação no Brasil, e são maioria em praticamente todas as áreas do conhecimento. Exceções encontram-se nas áreas de Exatas. Nos cursos de Engenharia, Produção e Construção, 30,2\% dos concluintes são mulheres, e nos cursos de Ciências, Matemática e Computação elas são 32,5\%.

Segundo Wajcman (2007), uma preocupação do movimento feminista é o acesso limitado das mulheres às instituições e profissões técnicas e científicas. A autora comenta que os processos pelos quais as meninas e os meninos são incentivados para assuntos diferentes, no ensino secundário e terciário, podem explicar a sub-representação das mulheres na educação científica, laboratórios e publicações científicas. Se as meninas tivessem oportunidades e fossem encorajadas, poderiam facilmente tornar-se cientistas e engenheiras. Ainda segundo esta autora, a tecnologia tem uma imagem masculina, não só porque é dominada por homens, mas porque incorpora símbolos, metáforas e valores que possuem conotações masculinas. Então, a relutância das mulheres pode estar relacionada também ao estereótipo de que a tecnologia é atividade apropriada para os homens. Uma situação que ameaça um indivíduo ser negativamente estereotipado, ser julgado ou tratado de forma estereotipada ou a possibilidade de se conformar ao estereótipo de um determinando grupo social ao qual o indivíduo se identifica é chamada por Steel (1997) de ameaça de estereótipo. Tópico amplamente estudado na psicologia social, as pesquisas têm evidenciado redução do desempenho de indivíduos que pertencem a grupos negativamente estereotipados. Isso porque se os estereótipos negativos estão presentes em relação a grupos específicos, é provável que os membros desses grupos se preocupem e fiquem mais ansiosos com o seu desempenho, o que pode dificultar sua capacidade de desempenhar no seu nível máximo (STEELE, 1997; STEELE; SPENCER; ARONSON, 2002). Este fenômeno pode explicar por que mulheres tendem a não escolher formação superior em ciências exatas e, posteriormente, profissões na área de tecnologia. 
Wacjman (2007), no entanto, observa que, com a proliferação de smartphones e internet, novas oportunidades e mercados estão surgindo para as mulheres. Isso acontece principalmente nos países altamente industrializados, que estão em melhor posição para tirar proveito dessas tecnologias, e, particularmente, entre as mulheres jovens, que se relacionam de forma diferente com novas tecnologias em comparação com as gerações anteriores. Contudo, levando em consideração a pequena participação feminina nesse setor, esta mudança de comportamento das mulheres jovens ainda não pode ser percebida.

Correll (2001) desenvolveu um estudo em que aponta como as crenças culturais podem influenciar as decisões de carreira para homens e mulheres jovens. O estudo foi realizado utilizando os dados do National Educational Longitudinal Study (1998) dos Estados Unidos, e se concentrou nos alunos de ensino médio. O resultado revelou que os meninos se avaliam melhor no que diz respeito às suas competências em matemática do que as meninas, mesmo quando ambos possuem as mesmas notas. $O$ estudo demonstra que esse resultado é o reflexo da crença cultural de que homens são melhores em matemática do que as mulheres e, consequentemente, afeta as escolhas de carreira desses indivíduos.

Em um estudo realizado com 80 estudantes do primeiro ano de graduação de uma universidade dos Estados Unidos, Correll (2004) demonstra que a aspiração dos indivíduos para uma carreira é formada com base na percepção de suas competências para tarefas que são relevantes para essas carreiras, como, por exemplo, a habilidade matemática para engenheiros. E essas percepções são influenciadas pelas crenças culturais sobre gênero que esses indivíduos possuem. Esses resultados refletem os vieses inconscientes. Ross (2014) afirma que mesmo quando nossos vieses parecem ser conscientes, eles podem ser influenciados por um padrão de suposições inconscientes absorvidos ao longo da vida.

$\mathrm{Na}$ tentativa de aumentar o interesse das meninas pela área de tecnologia em diversos países, empresas como Ericsson, Cisco e Oracle tornaram-se parceiras de programas como o Girls in ICT (http://girlsinict.org), que tem como objetivo criar um ambiente que capacite e incentive meninas e mulheres jovens a considerar carreiras no setor de Tecnologias de Informação e Comunicação. O Massachusetts Institute of Technology (MIT) possui um programa que promove e incentiva a participação de mulheres nos cursos de graduação e pós-graduação em Matemática, chamado MIT Women in Mathematics (http://math.mit.edu/wim/).

No Brasil, algumas iniciativas similares têm sido adotadas para incentivar o aprendizado das meninas em áreas da Ciência Exata e o ingresso em carreiras tecnológicas. No âmbito nacional o Edital MCTI/CNPq/SPM-PR/Petrobras no 18/2013 - Meninas e Jovens Fazendo Ciências Exatas, Engenharias e Computação - concedeu apoio financeiro a projetos que visem estimular a formação de mulheres para as carreiras de ciências exatas, engenharias e computação no Brasil, combatendo a evasão que ocorre principalmente nos primeiros anos destes cursos e despertando o interesse vocacional de estudantes do sexo feminino do Ensino Médio e da Graduação por estas profissões e para a pesquisa cientifica e tecnológica. Contemplado por este Edital o projeto Meninas na Ciência, iniciativa da Universidade Federal do Rio Grande do Sul (UFRGS), teve como objetivo atrair meninas para as carreiras de Ciência e Tecnologia (C\&T) e estimular mulheres que já escolheram estas carreiras a persistirem e se tornarem agentes no desenvolvimento científico e tecnológico do Brasil (BRITO; PAVANI; LIMA JR, 2015).

O projeto Futuras Cientistas, do Centro de Tecnologias Estratégicas do Nordeste (CETENE), seleciona alunas de ensino médio de escolas públicas de Recife (PE) para participarem em projetos de pesquisa 
desenvolvidos nos laboratórios de nanotecnologia, microscopia eletrônica e biocombustível, sob a orientação de um pesquisador responsável com um plano de trabalho que envolve o desenvolvimento de um projeto de pesquisa. O projeto "A Menina que Calculava", instituído na Universidade de Brasília, auxilia e incentiva meninas a se envolverem com as áreas de exatas (FREIRE, 2017). A L'Oréal Brasil promove desde 2006, em parceria com a UNESCO BRASIL e com a Academia Brasileira de Ciências, o Programa "Para Mulheres na Ciência". O Programa tem como motivação a transformação do panorama da ciência no País, favorecendo o equilíbrio dos gêneros no cenário brasileiro e incentivando a entrada de jovens mulheres no universo científico. (https://www.paramulheresnaciencia.com.br/o-premio/programa-nacional/).

\section{Mulheres, estereótipos e fadiga de gênero}

A teoria de congruência de papéis propõe que um grupo será avaliado positivamente quando suas características forem reconhecidas e alinhadas com os papéis sociais típicos. (EAGLY; KARAU, 2002). Por esta ótica, o preconceito contra as mulheres líderes ocorre, segundo as autoras, em razão de uma inconsistência percebida entre as características da mulher e aquelas que um líder deve possuir. Uma avaliação menos favorável de mulheres para potencial posição de liderança ocorre porque as habilidades de liderança estão associadas ao estereótipo masculino e, ao mesmo tempo, o comportamento de liderança é menos desejado em mulheres do que em homens (EAGLY; KARAU, 2002).

Os estudos de Duehr e Bono (2006) sugerem que os estereótipos sobre as mulheres podem estar mudando. Gerentes do sexo masculino, em particular, parecem caracterizar as mulheres como menos passivas e submissas e mais confiantes, ambiciosas, analíticas e assertivas e, ainda, classificam-nas como mais adequadas à posição de líderes do que fizeram há 15 ou 30 anos. Os autores ponderam que uma explicação plausível para esse resultado é a mudança real de ponto de vista dos gerentes do sexo masculino sobre as mulheres, e que esse fato pode ser um reflexo da mudança dos papéis sociais e/ou resultado de intervenções diretas, como treinamento para diversidade.

Kelan (2009) demonstra que a discriminação por gênero no setor de Tecnologia de Informação e Comunicação é um tema conhecido, mas que existiu no passado e que este tipo de incidente dificilmente ocorre nos dias de hoje. O dilema ideológico de saber que existe a discriminação por gênero e, ao mesmo tempo, conviver com a construção de um ambiente de trabalho neutro para gênero é caracterizado como fadiga de gênero. Isso significa que as pessoas sabem que existe a discriminação. Mas, como o ambiente de trabalho é construído de modo a evitar a discriminação, não é mais necessário fazer da discriminação de gênero um conceito. $O$ autor ressalta que a fadiga de gênero pode agravar o problema, uma vez que contribui para a falta de linguagem necessária para discutir as desigualdades estruturais entre homens e mulheres, tornando a desigualdade de gênero ainda mais difícil, senão impossível, de resolver.

Confirmando a teoria de congruência de papéis, algumas mulheres são avaliadas positivamente em seus papéis de líderes por possuírem as características masculinas de líder, como evidenciou uma pesquisa ampla realizada por Carvalho Neto, Tanure e Andrade (2010). A pesquisa quantitativa contou com uma amostra de 965 executivos (222 mulheres), e a qualitativa com 263 executivos (48 mulheres). Neste estudo, chamou atenção o fato de algumas executivas considerarem um elogio ser avaliadas com características 
masculinas, sem ao menos perceber o preconceito culturalmente arraigado que isso revela, observam os autores.

Um estudo realizado pela consultoria McKinsey (2015) em diversos países, com uma amostra de 1421 executivos ( 797 mulheres), revelou que $28 \%$ dos homens não acreditam que as mulheres enfrentam desafios para subir na carreira, enquanto apenas $5 \%$ das mulheres têm a mesma opinião. Não foram detalhadas neste estudo as áreas ou empresas a que os respondentes pertenciam.

\section{Barreiras na carreira profissional das mulheres}

Há mais de 20 anos o teto de vidro foi definido pelo Federal Glass Ceiling Commission dos Estados Unidos (1995), como uma barreira invisível e intransponível que impede as minorias e as mulheres de subir os degraus da escada corporativa, independentemente de suas qualificações ou realizações. Esta definição deixa claro que esse fenômeno é sutil, pouco perceptível e não passível de superação por membros à margem do grupo dominante.

Um estudo realizado com 40 altos executivos revelou que as principais barreiras que compõem o teto de vidro são os preconceitos, a discriminação, a capacidade de liderança, o conflito entre trabalho e família e a questão da maternidade (LIMA et al., 2013). Em estudo recente com executivos homens e mulheres das 500 maiores empresas localizadas no Brasil, Tanure, Carvalho Neto e Mota-Santos (2014) apontam que a principal barreira enfrentada por mulheres que chegaram a altas posições executivas diz respeito à necessidade de demonstrar mais competência e maior esforço no trabalho do que seus pares executivos.

Van Vianen e Fischer (2002) mencionam que a maioria das pesquisas sobre o teto de vidro se concentra nos mecanismos de exclusão e seleção e nas dinâmicas que a cultura organizacional pode formar como barreira para a ascensão das mulheres. As autoras argumentam, no entanto, que as mulheres não são meras vítimas de uma cultura dominante, e não são ativamente discriminadas, mas são também agentes de suas próprias carreiras, com suas motivações, desejos e preferências para trabalhar em determinada cultura. Sugerem que a auto-seleção, em termos de motivação e preferências, que influencia as decisões de carreira, pode afetar a carreira das mulheres tanto quanto a seleção efetuada por outros. A questão levantada por Van Vianen e Fischer (2002) é o que os homens e as mulheres acham atraente em uma cultura organizacional, e como essas preferências culturais afetam suas ambições gerenciais. O estudo realizado pelas autoras evidenciou que, em geral, os gerentes demonstraram maior preferência por competição e pressão no trabalho do que os indivíduos não gerentes. As mulheres, por sua vez, manifestaram menor preferência por competição e pressão no trabalho, e demonstraram menos ambição do que os homens em alcançar posições gerenciais mais elevadas, colocando menos esforço para este fim. Outro resultado importante foi que as mulheres percebem que o conflito entre casa e trabalho é uma das principais barreiras para aceitar uma posição gerencial sênior.

Eddleston, Baldridge e Veiga (2004) identificaram que as mulheres têm menor probabilidade de ser promovidas que os homens, mesmo em igual nível de desempenho. Os autores sugerem que o teto de vidro seja o motivo para esse resultado.

Oakley (2000), ao investigar as barreiras para as mulheres atingirem altos cargos executivos, identificou que o estereótipo baseado em gênero e o círculo fechado do "old boy networks" são forças sociais muito 
fortes e, por isso, podem demorar um longo tempo para mudar. O "old boy networks" é uma estratégia para prevenir a ameaça da ascensão feminina ao status quo masculino.

\section{Estratégias para superar as barreiras na carreira profissional das mulheres}

As mulheres procuram superar as dificuldades de ascensão na carreira com estratégias individuais ou algum tipo de suporte das organizações.

Ragins, Townsend e Mattis (1998) realizaram ampla pesquisa com 461 mulheres executivas e 325 CEOs, na qual foram reveladas as principais estratégias adotadas pelas mulheres para quebrar o teto de vidro: 1) exceder as expectativas de desempenho constantemente; 2 ) desenvolver estilo, de modo que os homens se sintam confortáveis e que não se sintam ameaçados. Para isso, as mulheres não devem possuir características muito masculinas nem muito femininas; 3) buscar por atribuições ou tarefas difíceis e que proporcionem visibilidade; 4) mentoring; 5) network.

No estudo de Orser, Riding e Stanley (2012) com 115 mulheres membros do Canadian Women in Technology, as formas mais citadas para superar as barreiras era em nível individual, tais como mudanças nas ações, no comportamento e nas credenciais (como a educação). A segunda forma dizia respeito ao mentoring ou network. Esta categoria reflete apoio psicossocial para ajudar a superar os desafios da carreira. Apesar de mentoring ser um programa frequentemente oferecido pelas grandes empresas de tecnologia a seus funcionários, algumas mulheres declararam ter a percepção de que, devido à baixa representatividade feminina no setor de tecnologia, os mentores homens preferem ser mentores de homens.

Ibarra, Carter e Silva (2010) informam, em seu estudo, que mais mulheres relatam receber mentoring do que homens. Se isso acontece, por que elas não estão conquistando mais posições gerenciais? Uma razão pode ser que as mulheres possuem mais mentores do que "patrocinadores", ao contrário dos homens, que possuem mais "patrocinadores". A diferença principal entre mentores e patrocinadores é que estes vão além do feedback e do aconselhamento. Patrocinadores defendem seus orientados, ajudam-nos a ganhar visibilidade na empresa e brigam para conseguir levá-los ao próximo nível.

\section{PROCEDIMENTOS METODOLÓGICOS}

A pesquisa realizada neste trabalho foi qualitativa, de caráter exploratório e descritivo, pois pretendeu entender qual a percepção de determinado grupo (masculino) com relação a certa situação (ascensão feminina na carreira). A intenção do pesquisador é extrair sentido ou interpretar os significados que os outros dão ao mundo (CRESWELL, 2010).

Foram realizadas oito entrevistas semiestruturadas com homens em cargos executivos (dois gerentes e seis diretores), da área técnica de uma empresa de tecnologia. O critério de escolha dos sujeitos foi por conveniência (PATTON, 1990), com a exigência de que esses executivos tivessem alguma experiência, passada ou atual, em trabalhar com mulheres executivas na área técnica. Todos os entrevistados têm formação em Engenharia, com faixa etária entre 39 e 51 anos. A área técnica da empresa responde pela entrega de serviços e produtos tecnológicos para os clientes finais. 
As entrevistas foram conduzidas mediante um roteiro com perguntas abertas. Inicialmente, o corpus da pesquisa consistiu, inicialmente, de três entrevistas integralmente analisadas. Com base nessa primeira fase, mais entrevistas foram realizadas até que seu conteúdo não contribuía com novas informações, configurando uma repetição dos dados, como mencionado por Denzin e Lincoln (1994). No total foram efetuadas oito entrevistas. Os sujeitos foram codificados como E1, E2, E3, E4, E5, E6, E7 e E8.

A empresa pesquisada é uma multinacional do ramo de tecnologia, possui um programa de diversidade e inclusão focado em diversidade de nacionalidade, pessoas com deficiência, orientação sexual e gênero. Em relação à diversidade de gênero, iniciativa implantada globalmente em 2014, foi definida uma meta de 30\% de mulheres em seu quadro de funcionários e dirigentes, em todo o mundo, até 2020.

A área técnica da empresa no Brasil possui 2.548 funcionários, sendo $14 \%$ mulheres e $4 \%$ executivos (gerentes ou diretores). Do total de cargos executivos, 19\% são ocupados por mulheres. É interessante observar que a representatividade feminina no nível executivo (gerentes e diretoras) é relativamente maior do que no quadro geral de funcionários.

A análise dos dados seguiu a lógica indutiva de pesquisa qualitativa, adotando-se os procedimentos definidos por Creswell (2010): realizar entrevistas, analisar os dados a partir de categorias, buscar padrões, generalizações ou teorias com base nas categorias e, por fim, fazer as generalizações ou teorias a partir das experiências passadas e da literatura. A seguir, os passos do processo de análise dos dados.

Passo 1 - organizar e preparar os dados para análise: transcrever literalmente as entrevistas, leitura geral do material, digitar anotações de campo.

Passo 2 - leitura dos dados: obter uma percepção geral e refletir sobre os resultados.

Passo 3 - fazer uma análise detalhada dos dados com um processo de codificação, organizando o material em blocos de textos, atribuindo significado às informações e transformando esses significados em categorias.

Passo 4 - relacionar dados com o tema e o referencial teórico.

Passo 5 - interpretação dos resultados, com as lições aprendidas pelo pesquisador.

O passo final envolve a interpretação dos dados ou extração de significados, que pode ser associado a uma comparação entre a fundamentação teórica e os dados coletados (CRESWELL, 2010).

\section{ANÁLISE E DISCUSSÃO DOS RESULTADOS}

A análise e a interpretação dos resultados foram estruturadas em torno de quatro categorias, derivadas dos discursos dos executivos entrevistados: Formação e Educação, Percepção de Barreiras, Valorização da Mulher e Aspectos Institucionais.

\section{Formação e Educação}

Quando questionados sobre qual o fator que eles acreditam ser a causa da baixa representatividade de mulheres nos quadros executivos em uma empresa de tecnologia, todos os entrevistados associaram o fato à escolha das mulheres na sua formação acadêmica. Um número baixo de mulheres graduadas em cursos de natureza técnica reflete diretamente na quantidade de mulheres que atuam na área técnica e, por 
sua vez, deve se refletir nas posições executivas das empresas de tecnologia. Algumas falas evidenciam essa lógica:

\begin{abstract}
Acho que isso bate desde o incentivo na escola, na escolarização. Eu sou engenheiro, na minha sala de engenheiros eu fiz uma boa faculdade, tive a sorte de fazer uma boa faculdade, e de uma sala de 54 pessoas, só tinha três mulheres. (E4)
\end{abstract}

Formação. Quando eu entrei na Engenharia, o próprio curso técnico era predominantemente masculino, então obviamente os profissionais que saem desses cursos tem mais homens, por isso que é predominantemente masculino. (E8)

Todos os entrevistados revelaram que, em suas turmas de engenharia, não se lembram de haver mais do que quatro mulheres em turmas de trinta a quarenta alunos. A percepção dos entrevistados é coerente com os dados referentes à quantidade de mulheres graduadas em áreas como Engenharia, Produção, Construção, Ciências, Matemática e Computação no Brasil, que é consideravelmente inferior à de homens.

Alguns entrevistados entendem que cursos na área técnica não são atrativos para mulheres (E3). A origem disso pode estar no estereótipo do papel de meninos e meninas desde a infância, como relata E5:

Primeiro que os cursos técnicos eles não são atrativos para as mulheres né [...] eu tenho essa percepção que poucas mulheres se formam nessa área. (E3)

Nenhuma criança, nenhuma menina, quando está lá brincando, quer desmontar o rádio. Começa por aí. Nenhuma menina se questiona o que está dentro da televisão. Acho que vem daí, ou seja, na hora de decidir a faculdade, a menina vai para (outra área) e o menino vai escolher Engenharia por uma característica do que ele viveu na infância. (E5)

Essa percepção que os entrevistados possuem sobre as diferenças na socialização confirmam o que Wajcman (2007) comenta sobre os processos pelos quais meninas e meninos são incentivados para assuntos diferentes no ensino secundário e terciário; além disso, reforça a imagem masculina que a área de tecnologia possui.

E6 mostra dificuldade em entender os motivos que levam meninos e meninas a escolherem determinadas profissões. Uma das razões pode residir nas crenças culturais, que podem influenciar as decisões de carreira para homens e mulheres jovens (CORRELL, 2001).

Não sei de onde vem. Não sei se isso é nato dos meninos ou se tem alguma questão cultural que leva os meninos a brincar com coisas de montagem. A razão principal tem a ver com a formação, agora, por que a maioria dos engenheiros é menino eu não consigo constatar. (E6)

Para alguns entrevistados, esse cenário parece estar mudando ao longo do tempo, com a entrada crescente de mulheres no setor.

Em compensação na Engenharia, no design, na área de TI tem bastante. A área de TI não é uma área exclusivamente masculina. Tecnologia de informação, onde você lida mais com softwares, sistemas e tal, aí já é uma outra formação, inclusive a área de Computação. Na área de Computação a presença de homens e mulheres nas faculdades é um pouco mais equilibrada do que na Engenharia (E1) 
Eu acho que está mudando [...], o número de mulheres se formando em tecnologia está aumentando, elas são tão competentes e capacitadas quanto os homens e as oportunidades estão aparecendo. Então agora estão de igual para igual, concorrendo com a gente, com os homens. (E2)

$\mathrm{O}$ avanço e o acesso às tecnologias pessoais pode ser um fator importante para a mudança revelada na opinião de E2. Em uma sociedade na qual a vida se torna cada dia mais conectada às novas tecnologias (networked society), pode-se supor que exista alguma influência dessa "sociedade conectada" na escolha da formação acadêmica dos indivíduos?

\section{Percepção de Barreira: "yo no creo en brujas, pero que las hay, las hay"}

\section{Desconhecimento ou não percepção de barreiras}

Os entrevistados relataram não perceber que as mulheres enfrentam barreiras na empresa para ascenderem à carreira executiva, por uma questão exclusiva de gênero. No entanto, um deles reflete sobre a situação:

\footnotetext{
É difícil falar assim, eu não vejo. Eu não sei, como eu não participei, eu não tenho nenhuma barreira contra mulher... e nas próprias conversas que eu tenho com a minha gerente, que se reporta para mim, ela também enxerga que pelo fato de ser mulher, ela não vê nenhuma resistência e que jamais ela se sentiu oprimida ou deixada de lado pelo fato de ser mulher [...]. (E3)
}

Aqui não, é o contrário hoje, as pessoas buscam colocar as mulheres no comando. Eu nunca vi [...] Ela pode ter alguma dificuldade por não ter competência técnica, mas não é pelo sexo. (E4)

Eu reflito sobre isso às vezes porque esse é um grande tema que eu vejo o tempo todo, e eu sempre falo que eu não vejo isso tão claro, não sei se eu que sou desatento, ou se pelo número, que são poucas mulheres, então eu conheço poucos casos. (E6)

Eu particularmente não vi nenhum ato nesse sentido, mas não duvido, infelizmente, que elas tenham sofrido mais do que outros para chegar nesse tipo de posição. (E8)

Algumas suposições podem ser questionadas. Poderia este fenômeno ser explicado pela falta de contato direto com mulheres que vivenciaram barreiras? Esses executivos não percebem indícios de dificuldade das mulheres por serem eles, predominantemente, os tomadores de decisão sobre a carreira das mulheres e, por isso, imaginam proporcionar igualdade de oportunidade? Ainda, as mulheres revelariam para seus chefes e pares eventuais discriminações vivenciadas no ambiente de trabalho?

Faz sentido a teoria da fadiga de gênero evidenciada por Kelan (2009)? Assim, em que medida a percepção dos executivos, acerca da ausência de barreira para as mulheres ascenderem, denota que a discriminação por gênero no setor de tecnologia é um tema que existiu no passado e hoje em dia não ocorre mais? A existência de um programa de diversidade de gênero pressupõe que o ambiente de trabalho seja construído para evitar a discriminação, contribuindo assim para o fenômeno da fadiga de gênero. Vale salientar que a fadiga de gênero pode encobrir um problema, ao deixar de ser discutido. 


\section{Discriminação: uma barreira velada}

Os homens entrevistados relatam nunca ter presenciado ou ouvido relatos de discriminação contra as mulheres, mas acabam refletindo e relatando que existe essa possibilidade. $\mathrm{Na}$ fala de alguns dos entrevistados havia certa dificuldade em entender e/ou perceber se existe realmente discriminação contra as mulheres. Existe então a possibilidade de haver uma discriminação velada, em que os gestores discriminam, mas não revelam, uma vez que a discriminação não é um comportamento bem aceito nas organizações?

\footnotetext{
Não. Nunca vi. Não sei se é uma coisa escondida, as pessoas falam não, imagina, não tem problema nenhum, mas na hora corta... é difícil de avaliar por que você escolheu um homem, não escolheu uma mulher, por que não ela (E3)
}

Eu particularmente não vi nenhum ato nesse sentido, mas não duvido, infelizmente, que elas tenham sofrido mais do que outros para chegar nesse tipo de posição (E8)

Eu acho que nas empresas sempre existiu um pouco de receio dos homens estarem subordinados às mulheres. Eu acho que isso existe. Eu acho que sempre existiu, existe menos hoje, existe menos ainda na nossa empresa. (E1)

Novamente, faz sentido a constatação da fadiga de gênero (KELAN, 2009)? Caso exista a discriminação acobertada pela fadiga de gênero, o problema pode ser realmente agravado com a falta de discussão sobre o assunto.

Aparentemente, esse não parece ser o caso da empresa pesquisada, que implantou em 2014 um programa de diversidade voltado ao gênero, cuja meta é alcançar até 2020 uma representação de 30\% de mulheres entre todos os funcionários e dirigentes. Embora um programa de diversidade seja construído para evitar a discriminação, importa considerar que é uma iniciativa recente e que pode não refletir as práticas de gestão em curso. Nesse aspecto, as questões de gênero podem não ter alcançado ainda esse estágio de "fadiga", ressaltado por Kelan (2009). Entretanto, a existência de um programa de diversidade poderia inibir comentários espontâneos sobre possíveis discriminações contra as mulheres.

\section{Barreira individual}

Outro fator considerado como barreira para o crescimento profissional feminino é a escolha entre trabalho e vida pessoal e a falta de ambição:

[...] a mulher, ela vai ter sempre um determinado momento que optar entre carreira e maternidade (E1)

$\mathrm{Na}$ fala de E1 existe uma ideia preconcebida de que a mulher deve "sempre" optar entre carreira e maternidade, ou seja, a carreira será prejudicada caso a mulher opte pela maternidade. Essa parece ser uma visão herdada da sociedade patriarcal descrita por Freyre (1984) e refletida também na abordagem de Kergoat (2009). Para a autora, a divisão sexual do trabalho "é a forma de divisão social do trabalho decorrente das relações sociais de sexo" [...] organizados em dois princípios: "o da separação (existem trabalhos de homens e outros de mulheres) e o da hierarquização (um trabalho de homem 'vale' mais do que um de mulher) 
(KERGOAT, 2009, p. 67). Assim, os homens percebem barreiras femininas em consonância com sua ideologia cultural sobre o papel de gênero.

No entanto, para os entrevistados 5 e 7, a barreira não é imposta pelos aspectos culturais, mas é construída pela própria mulher. Para E5 isso pode ocorrer devido a uma falsa percepção de que existe discriminação, e comenta: "Acho que mesmo quando não tem, a mulher coloca (E5)". A falta de ambição é um fator atribuído por E3, ao declarar que "[...] mesmo ela sendo super-boa no que faz, super-profissional, tudo, eu não a vejo com ambições de subir".

Van Vianen e Fischer (2002) declaram que as mulheres são responsáveis pelas suas carreiras, com suas próprias motivações, desejos e preferências, e encontram evidências de que o conflito família e trabalho é umas das principais barreiras para aceitar uma posição de liderança. Faz sentido considerar que o conflito família e trabalho é uma barreira imposta pela mulher a si mesma? Essa não seria uma barreira imposta por uma sociedade patriarcal, e, ao supor que a mulher impõe barreira a si mesma, uma forma de minimizar o problema causado pela discriminação de gênero?

$\mathrm{Na}$ fala de $\mathrm{E} 7$, outra colocação que remete a uma barreira criada pela própria mulher é a percepção de que as vagas para determinadas posições executivas são direcionadas para homens.

Mas já ouvi algumas mulheres falarem "senti que a vaga estava direcionada para homens", é uma percepção "do jeito que está escrito aqui, a posição, isso é para homem, não é para mulher", é uma percepção, porque as vagas são abertas a todos.

$(\mathrm{E} 7)$

Seria essa uma internalização feminina de que as organizações são tipificadas por gênero? Como afirmam Ely e Meyerson (1990), são "generificadas", pois políticas, práticas e normas tendem a refletir a experiência, valores e situações de vida masculina.

\section{Valorização da Mulher}

\section{Características positivas}

$\mathrm{Na}$ visão dos entrevistados, as mulheres são ou deveriam ser mais valorizadas. E se existe ainda alguma discriminação para a ascensão das mulheres, que impeça essa valorização, ela não deveria existir. Eles expressam algumas características positivas e vantagens:

Mas eu já vi mulheres gestoras e eu acho que, de uma forma geral, elas são exigentes, são dedicadas, são precisas. Eu não vejo diferença assim. Na verdade eu vejo uma diferença positiva que eu acho que a mulher é muito mais organizada do que o homem quando ela chega numa posição como essa, entendeu. (E1)

Sinceramente, acho que é interessante, porque você trabalhar com mulher de certa forma elas agregam, têm uma perspectiva, uma experiência diferente. Então eu acho que isso traz uma outra visão que às vezes a gente não tem no dia a dia. (E2) 
Eu prefiro trabalhar com mulher do que com homem, acho que a determinação, a preocupação e o resultado entregue pela mulher, de maneira geral, generalizando, é bem melhor [...] mulher na engenharia para analisar projeto, fazer projeto, ser detalhista, mulher na área de controle de custo não tem igual, na área de qualidade não tem igual.. (E5)

Se tem uma reunião só de homens, a gente meio que modela as conversas de um jeito que a gente não tem mais alguns inputs, que seriam interessantes para a gente tomar decisões. Quando tem a mulher aparecem ideias diferentes e novas [...] Vejo que tem o lado feminino trazendo mais ângulos que a gente não estaria vendo nas discussões. Então para mim isso é estratégico. (E7)

Os entrevistados avaliam positivamente as mulheres que ocupam o papel de líder sem fazer qualquer menção a características masculinas esperadas do papel de líder. Eles não entendem que as mulheres possuem ou devam possuir características específicas (masculinas ou femininas) para serem bem sucedidas. O entrevistado 7 menciona que faz parte de sua estratégia ter sempre, pelo menos, uma mulher em seu grupo de trabalho, devido aos benefícios que esse balanceamento entre homens e mulheres traz para o grupo. Esses achados contrastam com os argumentos da teoria da congruência de papéis (EAGLY; KARAU, 2002) de que as características femininas não são desejadas para o papel de líder, levando ao preconceito.

\section{Mais foco e mais esforço: superação de barreiras?}

$\mathrm{Na}$ opinião dos entrevistados, quando as mulheres possuem a ambição e a competência para assumirem posições executivas, elas são mais focadas e se esforçam muito mais do que os homens. Maior esforço, comentado pelos entrevistados E5 e E7, pode ser observado como uma estratégia que as mulheres encontraram para superar as barreiras.

Segundo Ragins, Townsend e Mattis (1998), a estratégia de maior importância revelada pelas mulheres em seu estudo foi a de, constantemente, exceder as expectativas de desempenho. $O$ desempenho superior é esperado de todos os executivos, mas para as mulheres isso é particularmente importante, e uma das razões para esse fato é que as pessoas não dão muita credibilidade à capacidade profissional das mulheres, então elas devem provar sua credibilidade a cada nova situação no trabalho. As falas dos executivos confirmam essa auto demanda de níveis mais elevados de desempenho das mulheres:

\footnotetext{
Quando vai para uma posição que tem um par homem, ela sempre acha que vai ter que correr mais do que o homem para ter o mesmo resultado. (E5)

Na minha organização eu tinha uma gerente que era muito preocupada com isso, de mostrar sempre algo a mais do que os gerentes homens estavam fazendo, para tentar se sobressair e mostrar assim que a escolha foi certa. (E7)
}

O estudo de Tanure, Carvalho Neto e Mota-Santos (2014) revelou a exigência de mais esforço por parte da mulher, citando uma executiva que relatou já ter trabalhado muitas noites para provar que ela é igual ou até melhor do que alguns colegas do sexo masculino.

O foco no maior esforço é encontrado na literatura como uma estratégia que as mulheres encontraram para superar barreiras, mas dependendo da perspectiva de análise de "mais esforço", este deve ser 
considerado como mais uma barreira a ser superada ou uma estratégia para superar as barreiras? Independente da perspectiva, o nível de esforço e o reconhecimento de esforço não deveriam ser diferentes para homens e mulheres.

\section{Aspectos Institucionais: iniciativas de diversidade}

Os entrevistados comentam sobre a iniciativa de diversidade das empresas, entendem o fato de as organizações estarem preocupadas com a questão e acreditam que são iniciativas importantes.

\footnotetext{
Eu acho que dentro de empresas grandes é muito natural que se tenha essas iniciativas de inclusão, de diversidade, empresas grandes com códigos de ética, principalmente multinacionais, eu passei por várias empresas grandes multinacionais e todas elas tinham isso assim muito claramente, e não se aceitava nenhum tipo de preconceito ou discriminação por sexo, por opção sexual muito menos também. Então é muito normal que se tenha um ambiente em que se limite o que a sociedade naturalmente faz. (E1).

Eu acho que as pessoas precisam começar a perceber que eles realmente se complementam, homem com mulher, têm pontos de vista diferentes e complementares, como empresa isso é ótimo, traz debate e discussão. (E4)

Eu entendo que é um mecanismo para chegar a um fim de um dia não precisar desse tipo de coisa [meta de número de mulheres no quadro de funcionários], acho que não deveria existir esse tipo de coisa, é um jeito que criaram para tentar movimentar a saída da inércia, mas para um dia chegar num ponto para não ter esse tipo de coisa (E8).
}

Percebe-se certo incômodo na fala de E8 com relação à empresa ter determinado uma meta percentual de número de mulheres no quadro de funcionários até 2020. Isso pode estar relacionado a uma meta de diversidade em quantidade, e não necessariamente na inclusão da diversidade. Essa meta pode ser parte da explicação para a maior representatividade feminina no nível executivo na área pesquisada no Brasil. Como todos os entrevistados fizeram algum comentário sobre essa iniciativa, também é possível notar que a iniciativa foi amplamente divulgada e é conhecida por todos.

Vale ressaltar que existe uma diferença entre um programa de diversidade e inclusão da diversidade. Para Ferdman (2014), inclusão da diversidade envolve a criação de um ambiente de trabalho em que as pessoas são valorizadas e apreciadas da forma como são, e a organização pode obter benefícios de sua diversidade.

\section{CONSIDERAÇÕES FINAIS}

Retomando o objetivo do artigo de identificar possíveis barreiras para a mulher atingir uma função executiva na área técnica, pode-se concluir que é difícil para os homens perceberem e relatarem se existem barreiras impostas ou oriundas de discriminação. Mas eles reconhecem que existem barreiras intrínsecas construídas pelas próprias mulheres.

Esse resultado poderia ser explicado por algumas razões: 1) realmente, os entrevistados não presenciaram e não perceberam nenhuma situação em que mulheres sofreram algum tipo de barreira; 2) os 
entrevistados preferiram, explicitamente, não revelar as barreiras, a fim de evitar uma imagem politicamente incorreta em uma empresa onde existe um programa de diversidade de gênero; 3) as referências que os entrevistados possuem de executivas são profissionais de sucesso e muito competentes, ficando, assim, as barreiras menos perceptíveis. 4) os entrevistados não conseguem perceber as experiências negativas enfrentadas pelas mulheres visto que não são diretamente afetados por elas e podem até ser favorecidos

A segunda explicação pareceu pouco provável, pois não se percebeu durante as entrevistas indícios dessa natureza. Contudo, não se pode descartar uma postura estratégica de "neutralidade em relação ao gênero" no mundo corporativo global. Um fato que pode também ter influenciado os resultados é um provável viés de gênero, pois a pesquisadora/entrevistadora era mulher. Isso pode ter inibido declarações mais espontâneas.

A primeira e a terceira explicações parecem mais prováveis pelo fato de os homens terem, supostamente, uma visão distante e até desinteressada sobre a carreira das mulheres, como se pôde inferir em algumas entrevistas. Parece que nunca tinham refletido sobre isso.

Finalmente, é plausível que a quarta explicação de que os homens não percebem as experiências femininas de dificuldades no trabalho e nem as barreiras de crescimento, pois eles não são diretamente afetados por tais situações vivenciadas pelas mulheres, podendo até serem favorecidos, principalmente em um ambiente de trabalho competitivo contagiado pela lógica masculina.

Cabe salientar que, mesmo não percebendo ou tentando se recordar de situações em que as mulheres teriam enfrentado possíveis barreiras, alguns entrevistados revelaram acreditar que barreiras existem. Curioso notar que os entrevistados percebem as barreiras que eles próprios não vivenciaram diretamente em sua função de gestores ou na condição de colegas. Essas barreiras simplesmente "existem" ou podem ter uma explicação cultural, e eles mesmos têm dificuldade de compreendê-las, como se: "yo no creo en brujas, pero que las hay, las hay".

Os resultados da pesquisa, de caráter exploratório, dão pistas relevantes para avançar o conhecimento sobre carreira de mulheres executivas na área de tecnologia, cujo ambiente é predominantemente masculino. Se esses homens constituem a maioria, com poder de decisão, e não percebem as barreiras oriundas do ambiente organizacional, mas percebem as barreiras construídas pelas mulheres, esse fator impõe um ônus maior sobre as mulheres e minimiza o papel do comportamento organizacional frente a esse fenômeno.

O conhecimento derivado da pesquisa mostra-se relevante para a gestão da diversidade em organizações da área de tecnologia. Uma reflexão importante para as empresas, principalmente as multinacionais, que tendem a aplicar as políticas de diversidade globalmente, é considerar as especificidades culturais e entender o limite de metas com caráter de cotas, que soam como "reserva de vagas" para as mulheres. Isso, provavelmente, geraria atitudes negativas por parte do mainstream, além de impor uma pressão adicional sobre as mulheres.

Uma contribuição para a sociedade que um estudo dessa natureza pode revelar é a necessidade de os órgãos públicos e universidades incentivarem mais o ingresso de jovens mulheres nas áreas de Ciências Exatas e Tecnológicas, para com isso aumentar a representação de mulheres no setor de tecnologia, vital para o desenvolvimento do país. 
Convém apontar como limitação a realização em uma única empresa de tecnologia. Salienta-se, também, que o fato de as entrevistas terem sido conduzidas por uma mulher pode, eventualmente, ter constrangido explicações mais espontâneas.

Para futuras pesquisas, sugere-se realizá-las em diversas empresas de tecnologia, com homens e mulheres, sobre a mesma temática, e confrontar os resultados. Outra vertente de pesquisa seria aprofundar as atitudes subjacentes dos executivos em relação à carreira de mulheres na área de tecnologia.

\section{REFERÊNCIAS}

APPLE. Inclusion \& Diversity. 2015. Disponível em <http://www.apple.com/diversity/>. Acesso em: 16 out. 2015.

AT\&T. Workforce Inclusion. 2015. Disponível em: <http://www.att.com/gen/corporate-citizenship?pid=17725>. Acesso em: 16 out. 2015.

BRASIL. Ministério da Ciência, Tecnologia e Inovação (MCTI). Centro de Tecnologias Estratégicas do Nordeste CETENE). Futuras Cientistas. Disponível em < http://www.sbq.org.br/noticia/institutos-de-pesquisa-do-mctic-queremdespertar-o-interesse-das-jovens-pela-ci\%C3\%AAncia>. Acesso em 06, mar, 2018.

BRASIL. Ministério da Ciência, Tecnologia e Inovação (MCTI). Conselho Nacional de Desenvolvimento Científico e Tecnológico (CNPq). Meninas e Jovens Fazendo Ciências Exatas, Engenharias e Computação. Disponível em: http://cnpq.br/chamadas-

publicas?p_p_id=resultadosportlet_WAR_resultadoscnpqportlet_INSTANCE_0ZaM\&filtro=abertas\&detalha=chamadaDiv ulgada\&idDivulgacao=4341. Acesso em 17 , mar, 2018.

BRASIL. Instituto Nacional de Estudos e Pesquisas Educacionais Anísio Teixeira (Inep). Resumo técnico censo da educação superior de 2013. Brasília, DF, 2015. p. 33. Disponível em: <http://portal.inep.gov.br/web/censo-da-educacaosuperior/resumos-tecnicos>. Acesso em: 18 fev. 2016.

BRITO, C.; PAVANI, D.; LIMA JR, P. Meninas na Ciência: atraindo jovens mulheres para carreiras de Ciência e Tecnologia. Gênero. v. 16, n.1, p. 33-50, 2015.

CARVAlHO NETO, A. M.; TANURE, B.; ANDRADE, J. Executivas: Carreira, Maternidade, Amores e Preconceitos. RAE - eletrônica, v. 9, n. 1, janeiro-junho, 2010.

CISCO. Corporate Social Responsibility Report. 2014. Disponível em <http://www.cisco.com/assets/csr/pdf/CSR_Report_2014.pdf\#page=40>. Acesso em: 16 out. 2015.

CORRELL, S. J. Gender and the Career Choice Process: The Role of Biased Self-Assessments. American Journal of Sociology, v. 106, n. 6, p. 1691-1730, 2001.

CORRELL, S. J. Constraints into Preferences: Gender, Status, and Emerging Career Aspirations. American Sociological Review, v. 69, n. 1, p. 93-113, 2004.

CRESWELL, John W. Projeto de pesquisa: métodos qualitativo, quantitativo e misto. 3. ed. Porto Alegre: Artmed, 2010.

DENZIN, N. K.; LINCOLN, Y. S. Handbook of qualitative research. Thousand Oaks: Sage, 1994.

DEUTSCHE TELEKOM. Women's quota - more women at the top. 2015. Disponível em <https://www.telekom.com/company/human-resources/diversity/58788>. Acesso em: 16 out. 2015

DUEHR, E. E.; BONO, J. E. Men, Women, and Managers: Are Stereotypes Finally Changing? Personnel Psychology, v. 59, n. 4, p. 815-846, 2006.

EAGLY, A. H.; KARAU, S. J. Role congruity theory of prejudice toward female leaders. Psychological Review, v. $109, \mathrm{n}$. 3, p. 573-598, 2002.

EDDLESTON, K. A.; BALDRIDGE, D. C.; VEIGA, J. F. Toward modeling the predictors of managerial career success: does gender matter? Journal of Managerial Psychology, v. 19, n. 4, p. 360-385, 2004.

ELY, R.J.; MEYERSON, D.E. Moving from gender to diversity in organizational diagnosis and intervention. Diversity Factor, v. 7, n. 3, p. 28-33, 1999.

ERICSSON. Diversity - Female representation. 2015. Disponível em http://www.ericsson.com/res/thecompany/images/diversity/div-fem-rep-full.jpg. Acesso em: 16 out. 2015.

EUROPEAN COMMISSION. Women active in the ICT sector. 2013. p. 34. Disponível em <http://www.bgwomeninict.org/language/bg/uploads/files/documents_0/documents_32b35cbb8f4815da69c1295eb5c2 9c99.pdf>. Acesso em: 16 out. 2015.

FACEBOOK. Driving Diversity at Facebook. 2015. Disponível em <https://newsroom.fb.com/news/2015/06/drivingdiversity-at-facebook/> Acesso em: 16 out. 2015. 
FEDERAL GLASS CEILING COMMISSION. Solid Investments: Making Full Use of the Nation's Human Capital. Washington, D.C.: U.S. Department of Labor, November 1995, p. 4.

FERDMAN, B. M. The Practice of Inclusion in Diverse Organizations: Toward a Systemic and Inclusive Framework. In: FERDMAN, B. M; DEAN, B. R. (Eds.) Diversity at Work: The Practice of Inclusion. Hoboken, NJ: John Wiley \& Sons, 2013. p. 3-54.

FREIRE, H.G. Distorção ano e idade no quinto ano do ensino fundamental: compreensões advindas da intervenção psicopedagógica. Trabalho final de curso de especialização em Psicopedagogia Clínica e Institucional, 2017.

FREYRE, G. Casa-grande e senzala. 23. ed. Rio de Janeiro: J. Olimpio, 1984.

GIRLS IN ICT. Disponível em <http://girlsinict.org/partners>. Acesso em: 10 nov. 2015.

GOOGLE. Diversity. Disponível em: <https://www.google.com/diversity/>. Acesso em: 16 out. 2015.

IBARRA, H.; CARTER, N. M.; SILVA, C. Why men still get more promotions than women. Harvard Business Review, v. 88 , n. 9, p. 80-85, set. 2010.

KELAN, E. K. Gender Fatigue: The Ideological Dilemma of Gender Neutrality and Discrimination in Organizations. Canadian Journal of Administrative Sciences, v. 26, n. 3, p. 197-210, 2009

KERGOAT, D. Divisão sexual do trabalho e relações sociais de sexo. In: HIRATA, H.; LABORIE, F.; LE DOARÉ, F.; SENOTIER, D. (Orgs.) Dicionário crítico do feminismo. São Paulo: Editora UNESP, 2009.

KIMBERLY A. EDDLESTON; DAVID C. BALDRIDGE; JOHN F. VEIGA. Toward modeling the predictors of managerial career success: does gender matter? Journal of Managerial Psychology, v. 19, n. 4, p. 360-385, 1 jun. 2004.

LIMA, G. S.; CARVALHO NETO, A.; LIMA, M. S.; TANURE, B.; VERSIANI, F. O teto de vidro das executivas brasileiras. Revista Pretexto, v. 14, n. 4, p. 65-80, 2013.

L'OREAL BRASIL. Programa Para Mulheres na Ciência. Disponível em <https://www.paramulheresnaciencia.com.br/opremio/programa-nacional/>. Acesso em 06, Mar, 2018.

MCKINSEY. A CEO's guide to gender equality. 2015. Disponível em:

<http://www.mckinsey.com/Insights/Leading_in_the_21st_century/A_CEOs_guide_to_gender_equality?cid=mckwomeneml-alt-mkq-mck-oth-1511>. Acesso em: 20 nov. 2015.

MICROSOFT. Global Diversity and Inclusion. 2015. Disponível em: <https://www.microsoft.com/en-us/diversity/insidemicrosoft/default.aspx>. Acesso em: 16 out 2015.

MIT WOMEN IN MATHEMATICS. Disponível em <http://math.mit.edu/wim/>. Acesso em: 18 fev. 2016.

OAKLEY, J. G. Gender-based barriers to senior management positions: Understanding the scarcity of female CEOs. Journal of Business Ethics, v. 27, n. 4, p. 321-334, 2000.

ORSER, B.; RIDING, A.; STANLEY, J. Perceived career challenges and response strategies of women in the advanced technology sector. Entrepreneurship \& Regional Development, v. 24, n. 1-2, p. 73-93, 2012

PATTON, M. Q. Qualitative evaluation and research methods. 4. ed. London: SAGE Publications, 1990.

RAGINS, B. R.; TOWNSEND, B.; MATTIS, M. Gender gap in the executive suite: CEOs and Female executives report on breaking the glass ceiling. The Academy of Management Executive, v. 12, n. 1, p. 28-42, 1998.

ROSS, H. J. Everyday bias. Lanham: Rowman \& Littlefield Publishing Group. 2014.

STEELE, C. M. A threat in the air: How stereotypes shape intellectual identity and performance. American Psychologist, v.52, n.6, p. 613-629, 1997.

STEELE, C. M; SPENCER, S. J.; ARONSON, J. Contending with group image: the psychology of stereotype and social identity threat. In ZANNA, M. P. (Ed.). Advances in experimental social psychology. v.34. Amsterdam: Academic Press, 2002, p.379-440.

TANURE, B.; CARVALHO NETO, A.; MOTA-SANTOS, C. Pride and prejudice beyond the glass ceiling: Brazilian female executives' psychological type. Revista de Ciências da Administração, v. 16, n. 39, p. 210-223, 2014.

VAN VIANEN, A. E. M.; FISCHER, A. H. Illuminating the glass ceiling: The role of organizational culture preferences. Journal of Occupational and Organizational Psychology, v. 75, n. 3, p. 315-337, 2002.

WAJCMAN, J. From Women and Technology to Gendered Technoscience. Information, Communication \& Society, v. 10, n. 3, p. 287-298, 2007. 